Melodie J. Fox. 2015. Epistemic Contrast in Medical and Legal Gender Classifications and their Influences on the Dewey Decimal Classification.

In Smiraglia, Richard P., ed. "Proceedings from North American Symposium on Knowledge Organization", Vol. 5.

Los Angeles, CA, pp. 112-114.

Melodie J. Fox

\title{
Epistemic Contrast in Medical and Legal Gender Classification and their Influence on the Dewey Decimal Classification
}

Hjørland (2010) writes, "The relative strengths and weaknesses of different [epistemic] approaches are an important research question for the field of KO" (p. 40). Determining who has the authority to speak, along with examining the decisions those authorities make, can reveal the epistemological perspective or perspectives at play. Interrogating the epistemic stance underlying a classification can help understand ontological decision-making process of the institution that claims the classification. In classifying groups of people, formal gender classifications can marginalize people who do not identify with traditional understandings of sex and gender. Sex, or biological characteristics, and gender, the social aspects associated with a particular sex, intertwine, and their characteristics can be conflated. Though in practice both gender and sex possess a great deal of variation and fluidity, most of the world considers them binary or some version of trinary, particularly in formal institutions. Western classification reinforces this rigidity with its principles of mutual exclusivity and hierarchical force. A formal sex or gender classification represents the sanctioned outlook of a particular institution, which then can affect people's lived experience.

This project shows how sex and gender been negotiated through medical and legal discourse, and how this has been represented in the Dewey Decimal Classification over time. Though preliminary slices of this research have previously been presented (e.g. Fox, 2014), this presentation reports the results of the investigation into the epistemic attitudes revealed in the discourse of each institution, how they correspond, and the consequences to those being classified. Identifying epistemic outlooks can, as Hjørland recommends, give us insight into what influence the particular epistemic stance has on the ontological decision-making in the creation of a bibliographic classification, and the consequences of taking that particular epistemic stance, both in terms of retrieval and in the respect accorded to the human groups as subjects.

\section{Methodology}

A discursive analysis was conducted of four editions of the $D D C$. The subjects or classes reviewed include those related to women, men, intersex, and trans people. The selected editions - first (1876), second (1885), seventeenth (1965) and the nineteenth editions (1979) —all indicate where a major change in classification for the concept of "woman" occurred. The particular editions of the $D D C$ were selected under the assumption that some force created a need for change in the ontological decision-making. To this end, this research asks how the specific institutions of medicine, psychology, and law acted as forces to influence change in the $D D C$ 's epistemic approach to "definitions" of sex and gender.

Thus, medical, psychological and legal discourses were examined to show shifts in the concepts of sex and gender relating to women, men, and intersex and trans people. The sex and gender definitions for each profession were drawn from the discourse of the fields. Following Foucault (1977), the concepts are not considered immutable and transcendent, but rather products of the interplay within and between the discourses. In professions such as medicine, the human body is an object of study, and sex is a concept that influences how other institutions 
Melodie J. Fox. 2015. Epistemic Contrast in Medical and Legal Gender Classifications and their Influences on the Dewey Decimal Classification.

In Smiraglia, Richard P., ed. "Proceedings from North American Symposium on Knowledge Organization", Vol. 5. Los Angeles, CA, pp. 112-114.

view it. Medical definitions of sex then directly influence other institutions, such as law, where sexual differentiation results in a specific application of the law to regulate rights and property that hinge on one's sex or gender. One discourse may or may not be more powerful than the other; however, Foucault would argue that no one institution dominates discourse, but rather together they, along with other influences, interplay to form a sense of a concept at a specific point in time.

Discourses investigated include medical and psychological research literature, medical dictionaries, medical jurisprudence texts, legislation, case law and legal dictionaries. All are based on American discourse, although in some instances British influence is present through medical journals or the Common Law. The analysis does not exhaustively review every mention of sex and gender in these discourses, but rather identifies what types of conceptualizations appear repeatedly to iteratively shape of the concept for that particular timeframe. For the $D D C$, the classification itself was analyzed, as well as the prefatory matter such as introductions, publisher's notes and other associated texts. The concepts, the methodological decision-making processes and justifications, as well as other epistemic clues such as the authority, rhetorical space (Code, 1995), user group interests (Hjørland 2001) and ontology were considered together to find a corresponding epistemic viewpoint that best matched what was expressed through the discourse. Once the approximate epistemic stance was identified, it was compared to the other discourses and the other timeframes.

\section{Findings}

The discursive analysis of medical, legal and $D D C$ discourses revealed first a contrast between the "professed" and "enacted" epistemology of each discursive body. The values of any given domain may be communicated in an ideal form, yet in practice an entirely different picture emerges. In other words, institutions may profess what epistemic goals they hold, but what is actually adopted may be different (Louca, et al., 2004, p. 59). The presentation will provide a more specific overview and the consequences of these professed and enacted epistemic stances concerning each of the selected gender classes - women, trans people and intersex peoplethroughout each timeframe by discourse. Then, the epistemic relationship between the medical and legal professions and the $D D C$ is discussed along with the implications to knowledge organization.

Over the century-long timeframe, the discourse revealed that women, trans people, and intersex people were all differentiated and defined in these discourses using a variety of epistemic outlooks, often reflecting and reinforcing social norms. In terms of knowledge organization, the epistemic analysis revealed the role of knowledge-generation processes in contributing to both the entrenchment and dismantling of institutionally-endorsed and -reinforced knowledge. In other words, through the discourse, the relationship between systematic and systemic becomes evident as individual reasoning methods are repeated until becoming nearly standard. It also shows the role of bibliographic classification in reflecting and replicating the epistemic values communicated through the discourse. Finally, it reveals that epistemic values as articulated can differ from how they are operationalized, and often they are not established in good faith, but can be built on self-interest. Formal classifications of sex or gender can hold authority as the "voice" of a particular institution and create an ontological definition with little or no subjectivity or agency for those being defined. 
Melodie J. Fox. 2015. Epistemic Contrast in Medical and Legal Gender Classifications and their Influences on the Dewey Decimal Classification.

In Smiraglia, Richard P., ed. "Proceedings from North American Symposium on Knowledge Organization", Vol. 5.

Los Angeles, CA, pp. 112-114.

\section{References}

Code, L. (1995). Rhetorical spaces: Essays on gendered locations. New York: Routledge.

Foucault, M. (1977/1980). Truth and power. In Colin Gordon, ed. Power/knowledge: Selected interviews \& other writings 1972-1977 (pp. 109-133). New York: Pantheon Books.

Fox, M.J. (2014) Medical discourse's influence on gender classification in three editions of the Dewey Decimal Classification. In Wiesław Babik, (ed.), Knowledge Organization in the 21st Century: Between Historical Patterns and Future Prospects: Proceedings of the 13th International ISKO Conference, May 19-22, 2014. Krakow, Poland. 228-225. Wurzburg: Ergon Verlag

Hjørland B. (2001). Brief communication: Towards a theory of aboutness, subject, topicality, theme, domain, field, content... and relevance. Journal of the American Society for Information Science and Technology, 52(9), 774-778.

Hjørland, B. (2010). Concepts, paradigms and knowledge organization. In C. Gnoli and F. Mazzocchi, (Eds.), Paradigms and conceptual systems in knowledge organization. Proceedings of the Eleventh International ISKO Conference 23-26 February 2010 Rome, Italy (Advances in knowledge organization, Vol. 12) (pp. 38-42). Würzburg: Ergon Verlag.

Louca, L. Elby, A., Hammer, D., \& Kagey, T. (2004). Epistemological resources: Applying a new epistemological framework to science instruction. Educational Psychologist, 39(1), 57-68. 